\title{
Sung melody enhances verbal learning and recall after stroke
}

\section{Leo, Vera}

2018-07

Leo , V , Sihvonen , A J , Linnavalli , T , Tervaniemi , M , Laine , M , Soinila , S \& Särkämö , T 2018 , ' Sung melody enhances verbal learning and recall after stroke ', Annals of the New York Academy of Sciences , vol. 1423 , no. 1 , pp. 296-307 . https://doi.org/10.1111/nyas.13624

http://hdl.handle.net/10138/300108

https://doi.org/10.1111/nyas.13624

acceptedVersion

Downloaded from Helda, University of Helsinki institutional repository.

This is an electronic reprint of the original article.

This reprint may differ from the original in pagination and typographic detail.

Please cite the original version. 


\title{
Sung melody enhances verbal learning and recall after stroke
}

\author{
Vera Leo, ${ }^{a}$ Aleksi J. Sihvonen, ${ }^{a, b}$ Tanja Linnavalli, ${ }^{a}$ M ari Tervaniemi ${ }^{a, c}$ M atti Laine, ${ }^{d}$ Seppo Soinila, ${ }^{e}$ and \\ Teppo Särkämöa
}

${ }^{a}$ Cognitive Brain Research Unit, Department of Psychology and Logopedics, Faculty of Medicine, University of Helsinki, Finland

${ }^{b}$ Faculty of Medicine, University of Turku, Finland

'CICERO Learning, University of Helsinki, Finland

dDepartment of Psychology, Åbo Akademi University, Turku, Finland

eDivision of Clinical Neurosciences, Turku University Hospital and Department of Neurology,

University of Turku, Finland

Corresponding author's contact information: Dr. Teppo Särkämö, Cognitive Brain Research Unit, Department of Psychology and Logopedics, Siltavuorenpenger 1B, P.O. Box 9, Fl-00014 University of Helsinki, Finland, E-mail: teppo.sarkamo@ helsinki.fi

Short Title: Sung melody enhances verbal learning after stroke

Key words: song; speech; verbal learning; stroke; aphasia

\begin{abstract}
:
Coupling novel verbal material with a musical melody can potentially aid its learning and recall in healthy subjects, but this has never been systematically studied in stroke patients with cognitive deficits. In a counter-balanced design, we presented novel verbal material (short narrative stories) in both spoken and sung formats to stroke patients $(\mathrm{N}=31)$ at the acute post-stroke stage and 6 months post-stroke. The task comprised three learning trials and a delayed recall trial. Memory performance on the spoken and sung tasks did not differ at the acute stage, whereas sung stories were learned and recalled significantly better compared to spoken stories at the 6-month post-stroke stage. Interestingly, this pattern of results was evident especially in patients with mild aphasia, in whom the learning of sung vs. spoken stories improved more from acute to 6-month stage compared to nonaphasic patients. Overall, these findings suggest that singing could be used as a mnemonic aid in the learning of novel verbal material in later stages of recovery after stroke.
\end{abstract}




\section{Introduction}

There are many common examples of mnemonic songs that are used in the learning of different kinds of verbal material, such as letters of the alphabet (Alphabet song) or notes of a musical scale (Do-Re-M i song). Experimental studies have shown that hearing the melody of a well-known song can effectively cue the retrieval of its lyrics [1] and previously unknown song lyrics that are learned together with a specific melody are better recognized later when paired with their original vs. new melody [2-4]. These findings suggest that when songs are learned through repeated exposure, the verbal (lyrics) and tonal (melodies) memory codes become at least partially integrated during encoding, with one facilitating the recognition of the other in delayed recall. However, evidence for the facilitating effect of melody on the learning of novel material in healthy subjects has been contradictory. In some studies, an enhancement of memory for sung vs. spoken novel material has been reported for the learning and/or delayed recall of connected text, such as song lyrics [5-8], slogans [9], and sentences [10], as well as unconnected text, such as word lists [11,12]. In other studies, no specific advantage for sung presentation has been found for song lyrics [13] or for word lists $[14,15]$.

These findings, though somewhat disparate, suggest that novel sung verbal material may be learned and recalled better than spoken material, but this effect seems to depend on a number of conditions. First, regarding the type of information to be learned, the effect appears to be more robust for multiple verses of connected text, in which individual units (words) are linked in a meaningful way, than for unconnected text. Second, the sung melody needs to be relatively simple and repeating across the verses, making it faster and easier to learn and also drawing attention to the surface characteristics of the text (e.g. phonemic and rhythmical properties, phrasing) that are accentuated by the melody [5]. Similarly, using statistical learning paradigms, the pre-attentive segmentation and learning of novel trisyllabic words has been shown to be enhanced when presented in sung vs. spoken format in adults [16] or in infant-directed speech vs. normal speech format in infants [17]. Third, the singing must be natural in terms of its tempo (speed in which words are pronounced), which tends to be around $50 \%$ slower than for speech. Speeding up the sung version to match the duration of the spoken version abolishes the effect [7]. Similarly, in the Racette et al. [13] study no advantage of sung presentation was observed when compared to a spoken presentation that had the same overall duration and was coupled with the melody sung on syllable /la/.

The extent to which the processing of lyrics and melody in songs is dissociated or integrated in memory is still under debate. While older lesion studies suggest dissociation between memory for lyrics and melodies [4,18], recent behavioral and functional magnetic resonance imaging (fM RI) studies have reported more integrated processing of lyrics and tunes across different frontotemporal regions, especially in the left hemisphere [19-21]. If through this integration melody really does provide an effective memory cue for verbal material it is coined with and in that way, increases the likelihood of better recall, then this could have implications for facilitating verbal learning especially in patients with language or cognitive (attention or memory) impairments due to neurological illness.

While the impact of singing-based interventions, such as melodic intonation therapy, for enhancing speech production has been a focus on intensive research [e.g., 22-24], very little is still known about the potential mnemonic effects of songs for learning and recall of novel verbal material in neurological patients. An advantage of sung material over spoken material has previously been observed in the learning and recall of word lists in multiple sclerosis (MS) patients [25] as well as in 
the recognition of unfamiliar song lyrics in Alzheimer's disease (AD) patients [26-28]. To date, only two studies have assessed the learning of unfamiliar song lyrics in stroke patients with chronic aphasia [29, 30]. In the case study Hébert et al. [29], a right hemisphere-lesioned, severely aphasic patient did not show better repetition of unfamiliar song lyrics when presented in sung vs. spoken format. Similarly, in the Racette et al. [30] (see Experiment 2) study, stroke patients with moderateto-severe aphasia ( $\mathrm{N}=8$ ) did not differ in the repetition of unfamiliar song lyrics when they were sung compared to when they were spoken with the melody (sung on syllable /la/) on the background.

The conclusions that can be drawn on the basis of the two previous stroke studies [29,30] are, however, limited by a number of methodological factors, including (i) the small number of subjects (would a larger sample show differences between the sung and spoken conditions?), (ii) the severity of aphasia (could persons with mild aphasia or no aphasia after stroke benefit more from the sung condition?), (iii) the type of song stimuli used (could lyrics with more concrete and narrative content show differences between the conditions?), (iv) protocol of the learning task (would longer verses with no line-by-line repetition during learning show differences between the conditions), and (v) design of the spoken comparison condition (would the conditions differ if the spoken condition did not include the background hummed melody?).

To address these questions, the present study sought to explore the learning and recall of entirely novel narrative stories (written and composed for the study) that were presented in both sung and spoken formats to 31 persons with stroke at acute and 6-month post-stroke stage to determine the mnemonic efficacy of songs at two stages of recovery. M oreover, given the heterogeneity of the cognitive symptoms caused by stroke depending on the location and extent of the lesion, we also sought to determine if learning and recall performance in the sung vs. spoken tasks would show a different pattern in three key deficits: language defits (aphasia), music perception deficits (amusia), and memory deficits. These deficits are all common after stroke, with an estimated incidence of around $30 \%$ for aphasia [31,32], 35-69\% for amusia[33,34], and 20-50\% for memory deficits [35, 36]. Although aphasia and amusia can occur separately, there is clear co-morbity between the disorders after stroke, with $40-50 \%$ of amusic persons also having at least mild aphasia [34,37,38]. Although aphasia and amusia are naturally associated with impaired processing of speech and musical melodies, respectively, the neural processing of vocal music (songs) seems to be relatively well preserved in these conditions after stroke [39]. M oreover, as dysfunctions in the left and right frontotemporal networks are the key underlying cause of aphasia [40-42] and amusia [37,43,44], respectively, the wide-scale and largely bilateral composition of the temporal, frontal, and limbic networks involved in the processing of songs [45-47] could potentially make them effective in both aphasia and amusia.

\section{Materials and Methods}

\section{Subjects and study design}

Subjects ( $N=31$ ) were stroke patients recruited during 2013-2016 from the Department of Clinical Neurosciences of the Turku University Hospital. All subjects had an MRI-verified unilateral acute stroke, primarily in the middle cerebral artery territory, and at least minor cognitive impairment caused by the stroke. Subjects with prior neurological or psychiatric disease, substance abuse, or significant hearing impairment were excluded. All participants underwent neuropsychological testing and an MRI within 3 weeks of the stroke (acute stage) and at the 6-month post stroke stage. The 
neuropsychological testing lasted 2-3 hours and was divided at acute stage into two shorter sessions if needed. The study was approved by the Ethics Committee of the Hospital District of Southwest Finland and was performed in conformance with the Declaration of Helsinki. All subjects signed an informed consent and received standard stroke treatment and rehabilitation.

\section{Standard neuropsychological tests}

Memory deficits were evaluated with the Story Recall (SR) subtest from the Rivermead Behavioural Memory Test (RBMT) [48] and an Auditory Wordlist Learning Task (AVLT). In the RBMT-SR, the subjects heard a short story once and were then asked to repeat everything they were able to recall from it, both immediately and after a 30-minute delay. Both immediate and delayed recall scores were used in the analyses. In the AVLT, a list of 10 words was presented orally three times, and after each presentation as well as after a 30-minute delay, the subjects were requested to recall as many words as they could. The summary score of the three learning trials and the delayed recall score were used in the analyses. Parallel versions of the memory tasks were used in different testing occasions to minimize practice effects.

Aphasia was assessed using the Aphasia Severity Rating Scale (ASRS) from Boston Diagnostic Aphasia Examination (BDAE) [49]. In addition to clinical observation, the performance of the subjects in three language tests was used to derive the clinical ASRS estimate: Verbal Fluency Test (VFT, listing words from a phonemic (letter) and semantic (animals) categories) [50], shortened Token Test (s-TT, following verbal instructions of simple tasks involving geometric shapes of different colors) [51], and shortened Boston Naming Test (s-BNT, naming 20 items from line drawings) [52]. Subjects with ASRS score of $\leq 4$ were classified as aphasic [49].

Amusia was evaluated by using a shortened version [34] of the Montreal Battery of Evaluation of Amusia (M BEA) [53] comprising the Scale and Rhythm subtests (discriminating piano melodies based on melodic pitch and rhythm changes). Subjects with M BEA total score $<75 \%$ correct were classified as amusic. Role of music in life pre-stroke was also assessed with the Barcelona Music Reward Questionnaire [54] at the acute stage.

The overall severity of stroke symptoms was assessed with the National Institute of Health Stroke Scale (NIHSS).

\section{Sung-spoken story recall task}

Stimuli. We developed the Sung-Spoken Story Recall Task (SSSRT) to compare the learning and recall of verbal material (stories) presented in sung and spoken formats. For this purpose, we created four short narrative stories (S1, S2, S3, S4), which all had a common theme of an unexpected or ironic event in everyday life (S1: driving home from a visit to grandmother and discovering on arrival that home keys were forgotten at grandmother's table, S2: meeting an old friend on the street and ending up cooking lunch with her, S3: forgetting a mobile phone to restaurant and later discovering that someone had made expensive hotline calls with it, S4: traveling to Spain on holiday and finding out that luggage was lost at the airport and arrives on the last day of the holiday). The stories were on average 57 words long (S1: 60, S2: 64, S3: 54, S4: 50) and all arranged in 5 verses. The duration of the spoken stories was on average $35.5 \mathrm{~s}$ (range 33-37 s). The duration of all the sung stories was $53 \mathrm{~s}$. Thus, the sung versions were $50 \%$ longer than the spoken versions, which is a usual ratio for sung vs. spoken material. We did not use a slowed spoken / speeded sung version as a control in order to keep the stimuli natural and ecological sounding and overall task duration bearable for the subjects. 
All the stories were recorded by the same female voice in (i) spoken format (with natural prosody) and (ii) in sung format. The sung versions of S1-2 and S3-4 had the same melodies, which were composed to be simple, containing 6-7 different tones in major (S1-2) / minor (S3-4) key in 4 bars, with $4 / 4$ meter and a tempo of 180 beats per minute (bpm). The same melody repeated in all the 5 verses of the song. The notation of the melodies is shown in Figure 1 and the full lyrics and audio versions of the spoken and sung stories are available as Supplementary Material.

Procedure. The spoken and sung versions of the SSSRT were presented to the subjects by counterbalancing the verbal content of the stories at different stages. Thus, at the acute stage, half of the subjects heard S1 spoken and S2 sung and half heard S1 sung and S2 spoken, and at the 6-month stage, half of the subjects heard S3 spoken and S4 sung and half heard S3 sung and S4 spoken. At both stages, the spoken task was always presented first, with three consecutive learning trials and a delayed recall trial 25 minutes later. Then, after a 15-minute interval, the sung task was presented following the same protocol. We chose to use this fixed presentation order instead of a counterbalanced order to avoid the possibility that when performing the sung version first, the subjects could then covertly use the melody (i.e., imagining or humming it in their mind) while performing the spoken version. This would have been possible since the story pairs (S1-S2 and S3-S4) were designed to have a matched linguistic structure (in terms of line length and phrasing) so that both would work with the same melody. The stimuli were presented on a laptop computer with headphones (the volume was adjusted to a comfortable and clearly audible level). On each trial, the task of the subject was always to recall as much of the story as he/she could. To make the recall situation as natural and comfortable as possible in the sung condition, the subjects were given the option of recalling the story either by speaking or by singing. All recall performances were done by speaking as none of the subjects chose singing.

Data analysis. The scoring protocol for the SSSRT was similar as in the RBMT-SR: 2 points for each correct word and 1 point for each partially correct or semantically similar word. The percentages of correct responses for each learning trial (1st trial, 2nd trial, 3rd trial) and the delayed recall trial were calculated. The difference between the sung and spoken task performance for each trial was analyzed statistically using paired t-tests and mixed-model analyses of variance (ANOVA) of the difference score between sung and spoken task performance (sung minus spoken). The level of statistical significance was set at $P<0.05$. All statistical analyses were performed using IBM SPSS Statistics 24 .

\section{Results}

\section{Subject characteristics}

Based on performance on the language tests (VFT, s-TT, s-BNT) and on the BDAE-ASRS scores, 14 subjects (45\%) were rated as aphasic (all with left hemisphere lesions) and 17 as non-aphasic. In the aphasia group, the severity of language impairment was primarily mild (10 subjects: BDAE-ASRS score 4, 4 subjects: BDAE-ASRS score 3). As shown in Table 1, the aphasic and non-aphasic groups did not differ in age, gender, formal musical training, pre-stroke musical hobbies, education, lesion size, NIHSS scores, or RBM T-SR performance. As expected, the aphasic group had lower scores than the non-aphasic group in AVLT learning $[\mathrm{t}(29)=2.9, \mathrm{P}=0.006]$ and delayed recall $[\mathrm{t}(29)=2.1, \mathrm{P}=$ $0.049]$ at the acute stage.

Based on performance on the M BEA Scale and Rhythm subtests, 16 subjects (52\%) were classified as amusic and 15 as non-amusic. The amusic and non-amusic groups did not differ in age, gender, 
education, pre-stroke musical hobbies, formal musical training, lesion size, or AVLT or RBM T-SR performance at acute stage (Table 1). However, the amusic group had higher NIHSS scores [t(23) =$2.5, P=0.018]$ at acute stage.

Based on performance on the verbal memory tests (RBM T-SR, AVLT), 16 subjects ( $52 \%$ ) were classified as having a more severe memory impairment (referred to hereafter as the memoryimpaired group) and 15 as having less severe or no memory impairment. These groups did not differ in most demographic ad clinical variables (Table 1), but the memory-impaired group had lower frequency of pre-stroke music listening.

\section{Sung vs. spoken story recall: Cross-sectional results}

At the acute post-stroke stage, a direct comparison between the sung and spoken story recall tasks using paired t-tests did not show any significant differences in performance between the two tasks across all subjects either in learning (1st trial, 2nd trial, 3rd trial) or in delayed recall (Figure 2A). Separate paired t-tests within the aphasic, amusic and memory-impaired subgroups also did not yield any significant effects. At the 6 -month post-stroke stage (Figure $2 \mathrm{~B}$ ), performance on the sung task was better than on the spoken task across all subjects in the $2 \mathrm{nd}[\mathrm{t}(30)=-2.8, \mathrm{P}=0.009]$ and 3rd $[\mathrm{t}(29)=-2.4, \mathrm{P}=0.023$ ] learning trials and in the delayed recall $[\mathrm{t}(30)=-3.6, \mathrm{P}=0.001]$. Separate paired t-tests in aphasic, amusic, and memory-impaired subgroups indicated that performance on the sung task was better than on the spoken task in the aphasic subgroup on the $2 \mathrm{nd}[\mathrm{t}(13)=-2.2$, $P=0.045]$ and $3 r d[t(13)=-2.8, P=0.015]$ learning trials, in the amusic subgroup on the delayed recall trial $[\mathrm{t}(15)=-2.4, \mathrm{P}=0.029]$, and in the memory-impaired subgroup on the 2 nd learning trial [t $(15)=-2.2, P=0.048]$ and delayed recall trial $[t(15)=-2.5, P=0.022]$.

\section{Sung vs. spoken story recall: Longitudinal results}

M ixed-model ANOVAs on the difference between the sung and spoken task performance (sung minus spoken) were performed with Time (acute / 6-month) as a within-subjects factor and Aphasia (non-aphasic / aphasic), Amusia (non-amusic / amusic), and M emory impairment (memory impaired / non-memory-impaired) as between-subjects factors. Separate ANOVAs were performed for the three learning trials (1st, 2nd, 3rd) and the delayed recall trial. These analyses yielded a significant Time $x$ Aphasia interaction for all the learning trials [1st trial: $F(1,23)=5.5, P=0.028 ; 2$ nd trial: $F(1,23)=12.7, P=0.002$; 3rd trial: $F(1,22)=5.2, P=0.033$ ], with the aphasic subjects showing a larger increase in the sung > spoken effect from the acute to the 6-month stage compared to the non-aphasic subjects (Figure 3A). In addition, there was a significant Time $x$ Amusia interaction for the delayed recall trial $[F(1,23)=5.7, P=0.025]$, with the amusic subjects showing a larger increase in the sung $>$ spoken effect from the acute to the 6-month stage compared to the non-amusic subjects (Figure 3B). There was a also significant three-way Time $x$ Aphasia $x$ M emory impairment interaction for the delayed recall trial $[F(1,23)=5.2, P=0.032]$. Separate mixed-model ANOVAs within the non-memory-impaired and memory-impaired subgroups showed that the longitudinal sung > spoken delayed recall effect in aphasic vs. non-aphasic subjects was significant only within the non-memory-impaired subgroup [Time $x$ Aphasia: $F(1,13)=5.6, P=0.034$, see Figure $3 C$ ], suggesting that those aphasic subjects who did not have concurrent memory impairment benefited most from the sung presentation of the material in delayed recall during the follow-up.

Relationship of SSSRT to memory performance and musical background 
Correlational analyses (Pearson, two-tailed) were performed to obtain further information about the relationship between SSSRT and performance in standard verbal memory tasks. At the acute stage, the AVLT learning score correlated significantly with the learning trials (average of three trials) of both the spoken $(r=.40, p=0.027)$ and sung $(r=.48, p=0.006)$ SRT and the RBMT-ST immediate recall with the 1st learning trial of both the spoken $(r=.62, p<0.001)$ and sung $(r=.59$, $p<0.001)$ SRT. Similarly, the delayed recall scores of both AVLT and RBM T-SR correlated highly significantly with the delayed recall trial of the spoken $(r=.79, p<0.001 ; r=.67, p<0.001)$ and sung $(r=.56, p=0.001 ; r=.48, p=0.006)$ SRT at the acute stage. These correlations between the tests were essentially the same at the 6 -month stage. These results suggest that the SSSRT is measuring the same memory processes as the standard verbal memory tests.

In order to determine if the learning and recall advantage of the sung vs. spoken presentation observed across patients at the 6-month stage was associated with the pre-stroke musical background of the subjects, we compared the sung >spoken effect (both learning and delayed trials) between patients with vs. without previous formal musical training and with vs. without previous musical hobby (singing or playing) with independent-samples t-tests. We also correlated the sung >spoken effect with the BM RQ scores indicating the importance and reward value of music. No significant effects were obtained in any of these analyses ( $p>0.1$ in all), suggesting that subjects with more active pre-stroke musical background did not show more benefits on sung vs. spoken task performance.

\section{Discussion}

The current study was set up to systematically investigate the learning and recall of novel narrative stories that were presented in both sung and spoken formats to 31 subjects affected by stroke longitudinally at two different recovery stages. The main finding was that subjects affected by stroke benefited from the sung melody as a mnemonic aid in recalling novel stories at 6 months post-stroke, but not at the acute stage. The positive effect of sung vs. spoken presentation was seen on the second and third learning trials but not on the first trial, suggesting that the effect builds up with repetition and rehearsal, as well as on the delayed recall trial. The benefit of the sung melody on story learning at 6 months was seen especially in subjects with mild aphasia, in whom this effect increased greatly from the acute stage. Also subjects with amusia and memory impairment showed enhanced delayed recall of the sung vs. spoken stories.

Previous studies in healthy subjects suggest that novel sung verbal material may be learned and recalled better than spoken material if (a) the text is connected; (b) the melody is simple, repeats across verses, and accentuates the surface characteristics of the text; and (c) the tempo of the singing is natural (slower than in speech) and the spoken version also has normal prosodic structure $[5-8,13]$. The task we used fits closely within this framework as (i) we used novel stories that were arranged in five verses and repeated over several learning trials; (ii) the content of the stories was concrete and narrative, with a clear storyline; (iii) the melodies were structurally simple and repeated across verses; and (iv) the singing was in natural tempo and the spoken version was in natural prosody. It is likely that these factors contribute to the advantage of learning and recall of sung vs. spoken material also in subjects affected by stroke observed here, by making the integration of the text and melody possible, and at the same time reducing the likelihood of generating of a dual-task situation where the melody and text are treated separately and are therefore more taxing for attention $[5,7,13,55]$. 
Aphasic subjects learned the sung stories better than the spoken ones at the 6-month stage whereas no significant differences were observed at the acute stage (aphasics performed slightly worse in the sung task at acute stage). Longitudinally, the aphasic subjects showed an increase in the sung >spoken effect from the acute to the 6-month stage in all learning trials. Those aphasic subjects who did not have memory impairment showed this effect also for delayed recall. The lack of an effect at acute stage may be related to the higher severity of verbal and cognitive deficits and post-stroke fatigue that is highly prevalent at the acute stage, affecting $25-75 \%$ of patients [57], making the task very difficult for the subjects. At this stage, it is plausible that due to general attentional deficits (e.g. attention shifting) and slowness of information processing [58] the subjects may have had difficulty in encoding the linguistic and musical (verbal and melodic) information in parallel, making the musical element a secondary task or an additional demand rather than an aid to memory. Compared to previous studies, which have not found any differences in the recall of sung and spoken material in aphasic subjects $[29,30]$, the advantage of sung over spoken material observed at the 6-month stage can be explained by methodological differences between the studies. First of all, the aphasic group in our study was larger $(\mathrm{N}=14)$ and had mild aphasia whereas previous studies have included only 1-8 patients with moderate-to-severe aphasia [29,30]. Second, the stories used here were more concrete and narrative in their content than the unfamiliar song lyrics used previously $[29,30]$. Third, compared to the adaptive learning paradigm and the divided spoken-sung comparison condition used previously [30], the task here was cognitively more demanding (recalling the entire story at the end of each trial) and the spoken comparison condition did not include a melodic cue, which may have accentuated the sung-spoken effect at the 6-month stage.

Also the amusic and the memory-impaired subjects showed an advantage of sung over spoken task performance in delayed recall (memory-impaired subjects also in the 2nd learning trial) at the 6month stage. In general, the positive mnemonic effects of the sung stories observed here in all patient subgroups are in line with similar findings from previous studies of persons with MS [25] and Alzheimer's disease [26-28]. At the neural level, these effects are most likely related to the bilaterality of the temporal, frontal, and limbic networks engaged in processing songs [45-47] and to the preservation of vocal music processing in spared brain regions previously reported in amusia and aphasia after stroke using fM RI [39]. Similarly, singing-based training has been observed to be beneficial both for enhancing speech production in aphasia [22-24] and singing production and music perception in amusia $[59,60]$. Given that our stroke sample here was non-selected with respect to specific symptoms or lesion locations, there is a natural overlap (co-morbidity) between the aphasic, amusic, and memory deficits (see Table 1). Therefore, we are not able reliably discern the specificity of the observed effects to each of these deficits. Although this makes the findings somewhat exploratory and descriptive, it does serve a clinical and pragmatic purpose in helping to identify what type of stroke patients might benefit from songs as a mnemonic aid in their rehabilitation. In future, it would be useful and valuable to perform this study using a larger sample of patients with specific and non-overlapping symptoms to better uncover the particular mnemonic effects of songs in each deficit.

In the present study, the verbal content of the sung and spoken versions was counter-balanced, but the presentation order was fixed, with the spoken task always performed first. This was deliberately done in order to avoid any potential facilitatory carry-over effects of the sung task on the spoken task when performing the sung task first (i.e. subjects imagining or humming the melody in their mind during the spoken task). Although this approach prevents the "mixing" of the tasks, it lends to the possibility that the fixed presentation order might have biased the results, with the later sung task benefiting from a practice effect. However, it is likely that this potential effect is offset by the 
increasing fatigue when performing the tasks (the SSSRT was relatively long and embedded in a larger neuropsychological testing battery; the sung task was final test of the session), which, in turn, would have had an impeding effect on performance on the sung task. Thus, overall, it is unlikely that the presentation order had significant effect on the observed results.

Also, the slower word presentation rate in the sung than spoken task may potentially have facilitated the recall of the sung stories, as slower rate gives more time to encode the lyrics; in our study, the duration of the sung versions was approximately $50 \%$ longer than the spoken versions. In principle, this effect could have been controlled for by including a slowed spoken / speeded sung version as a control, but we opted not do this (i) as it makes the stimuli unnatural and artificial sounding, which itself can attract the attention of the subject away from the content of the text and therefore introduce an additional unwanted element to the task, and (ii) due to time constraints associated with the testing in general. From a practical standpoint, the slower production rate is an inherent feature of singing (with the exception of some singing styles, e.g. rap) and an important component in its rehabilitative use in many neurological communication impairments, including aphasia [56].

In summary, the present results demonstrate, to our best knowledge for the first time that subjects affected by stroke, especially those with mild aphasia, benefit from sung melody as a mnemonic aid in the learning and later recall of novel verbal material 6 months post-stroke. While more research is still needed to explore potential benefits in patients with more severe aphasia and to uncover the neural basis of this effect, overall the present findings encourage the use of songs in memory rehabilitation after stroke. In future, the next step could be to test whether a longer intervention program utilizing sung melodies as a tool to train memory could have a long-term rehabilitative impact in stroke patients with verbal and memory deficits.

\section{Acknowledgements}

This work was funded by Academy of Finland (grants 1257077, 277693, 299044), National Doctoral Programme of Psychology, Finnish Cultural Foundation, and M iina Sillanpää Foundation, Finland We kindly thank the stroke patients for participating in the study and the staff of the Tyks Department of Clinical Neurosciences for their help.

\section{References}

[1] Rubin, D.C. 1977. Very long-term memory for prose and verse. J. Verbal Learning Verbal Behav. 16: 611-621.

[2] Serafine, M.L., R.G. Crowder \& B.H. Repp. 1984. Integration of melody and text in memory for songs. Cognition 16: 285-303.

[3] Crowder, R.G., M.L. Serafine \& B.H. Repp. 1990. Physical interaction and association by contiguity in memory for the words and melodies of songs. Mem. Cognit. 18: 469-476.

[4] Samson, S. \& R.J. Zatorre. 1991. Recognition memory for text and melody for songs after unilateral temporal lobe lesion: Evidence for dual encoding. J. Exp. Psychol. Learn. M em. Cogn.,17: 793-804.

[5] Wallace, W.T. 1994. Memory for music: effect of melody on recall of text. J. Exp. Psychol. Learn. Mem. Cogn. 20: 1471-1485.

[6] M cElhinney, M. \& J.M. Annett. 1996. Pattern of efficacy of a musical mnemonic on recall of familiar words over several presentations. Percept. M ot. Skills 82: 395-400.

[7] Kilgour, A.R., L.S. Jakobson \& L.L. Cuddy. 2000. M usic training and rate of presentation as mediators of text and song recall. M em. Cognit. 28: 700-710. 
[8] Purnell-Webb, P. \& C.P. Speelman. 2008. Effects of music on memory for text. Percept. M ot. Skills 106: 927-957.

[9] Yalch, R.F. 1991. Memory in a jingle jungle: music as a mnemonic device in communicating advertising slogans. J. Appl. Psychol. 76: 268-275.

[10] Calvert, S.L., \& M. Tart. 1993. Song versus verbal forms for very-long-term, long-term, and short-term verbatim recall. J. Appl. Dev. Psychol. 14: 245-260.

[11] Chazin, S. \& J.S. Neuschatz. 1990. Using a mnemonic to aid in the recall of unfamiliar information. Percept. M ot. Skills 71: 1067-1071.

[12] Rainey, D.W. \& J.D. Larsen. 2002. The effect of familiar melodies on initial learning and longterm memory for unconnected text. M usic Percept. 20: 173-186.

[13] Racette, A \& I. Peretz. 2007. Learning lyrics: to sing or not to sing? M em. Cognit. 35: 242-253.

[14] Jellison, J. A., \& N.L. M iller. 1982. Recall of digit and word sequences by musicians and nonmusicians as a function of spoken or sung input and task. J. M usic Ther. 19: 194-209.

[15] Thaut, M.H., D.A. Peterson \& G.C. M clntosh. 2005. Temporal entrainment of cognitive functions: musical mnemonics induce brain plasticity and oscillatory synchrony in neural networks underlying memory. Ann. N. Y. Acad. Sci. 1060: 243-254.

[16] Schön, D., M. Boyer, S. M oreno, et al. 2008. Songs as an aid for language acquisition. Cognition 106: 975-983.

[17] Bosseler, A.N., T. Teinonen, M. Tervaniemi, et al. 2016. Infant directed speech enhances statistical learning in newborn infants: an ERP study. PLoS One 11: e0162177.

[18] Hébert, S. \& I. Peretz. 2001. Are text and tune of familiar songs separable by brain damage? Brain Cogn. 46: 169-175.

[19] Fedorenko, E., A. Patel, D. Casasanto, et al. 2009. Structural integration in language and music: evidence for a shared system. Mem. Cognit. 37: 1-9.

[20] Sammler, D., A. Baird, R. Valabrègue, et al. 2010. The relationship of lyrics and tunes in the processing of unfamiliar songs: a functional magnetic resonance adaptation study. J. Neurosci. 30: 3572-3578.

[21] Schön, D., R. Gordon, A. Campagne, et al. 2010. Similar cerebral networks in language, music and song perception. Neurolmage 51: 450-461.

[22] Schlaug, G., S. Marchina \& A. Norton. 2008. From singing to speaking: why singing may lead to recovery of expressive language function in patients with Broca's aphasia. M usic Percept 25: 315-323.

[23] van der M eulen, I., W.M. van der Sandt-Koenderman, M.H. Heijenbrok-Kal, et al. 2014. The efficacy and timing of melodic intonation therapy in subacute aphasia. Neurorehabil. Neural Repair 28: 536-544.

[24] Zumbansen, A., I. Peretz \& S. Hébert. 2014. The combination of rhythm and pitch can account for the beneficial effect of melodic intonation therapy on connected speech improvements in Broca's aphasia. Front. Hum. Neurosci. 8: 592.

[25] Thaut, M.H., D.A. Peterson, G.C. M clntosh, et al. 2014. M usic mnemonics aid verbal memory and induce learning-related brain plasticity in multiple sclerosis. Front. Hum. Neurosci. 8: 395.

[26] Simmons-Stern, N. R., A. E. Budson \& B. A. Ally. 2010. M usic as a memory enhancer in patients with Alzheimer's disease. Neuropsychologia 48: 3164-3167.

[27] Moussard, A., E. Bigand, S. Belleville, et al. 2014. Learning sung lyrics aids retention in normal aging and Alzheimer's disease. Neuropsychol. Rehabil. 24: 894-917.

[28] Palisson, J., C. Roussel-Baclet, D. M aillet, et al. 2015. M usic enhances verbal episodic memory in Alzheimer's disease. J. Clin. Exp. Neuropsychol. 37: 503-517.

[29] Hébert, S., A. Racette, L. Gagnon, et al. 2003. Revisiting the dissociation between singing and speaking in expressive aphasia. Brain 126: 1838-1850. 
[30] Racette, A., C. Bard \& I. Peretz. 2006. Making non-fluent aphasics speak: sing along! Brain 129: 2571-2584.

[31] Engelter, S. T., M. Gostynski, S. Papa, M., et al. 2006. Epidemiology of aphasia attributable to first ischemic stroke: Incidence, severity, fluency, etiology, and thrombolysis. Stroke 37: 13791384.

[32] Flowers, H. L., F. L. Silver, J. Fang, E. et al. 2013. The incidence, co-occurrence and predictors of dysphagia, dysarthria, and aphasia after first-ever acute ischemic stroke. J. Commun. Disord. 46: 238-248.

[33] Schuppert, M., T. F. M ünte, B. M. Wieringa, et al. 2000. Reseptive amusia: Evidence for crosshemispheric neural networks underlying music processing strategies. Brain 123: 546-559.

[34] Särkämö, T., M. Tervaniemi, S. Soinila, et al. 2009. Cognitive deficits associated with acquired amusia after stroke: A neuropsychological follow-up study. Neuropsychologia 47: 2642-2651.

[35] Rasquin, S. M., F. R. Verhey, R. Lousberg, et al. 2002. Vascular cognitive disorders: M emory, mental speed and cognitive flexibility after stroke. J. Neurol. Sci. 15: 115-119.

[36] Lim, C. \& M. P. Alexander. 2009. Stroke and episodic memory disorders. Neuropsychologia 47: 3045-3058.

[37] Sihvonen, A. J., P. Ripolles, V. Leo, et al. 2016. Neural basis of acquired amusia and its recovery after stroke. J. Neurosci. 36: 8872-8881.

[38] Stewart, L., K. von Kriegstein, J. D. Warren, et al. 2006. Music and the brain: Disorders of musical listening. Brain 129: 2533-2553.

[39] Sihvonen, A. J., T. Särkämö, P. Ripolles, et al. 2017. Functional neural changes associated with acquired amusia across different stages of recovery after stroke. Sci Rep 7: 11390.

[40] Saur D., R. Lange, A. Baumgaertner, et al. 2006. Dynamics of language reorganization after stroke. Brain 129: 1371-1384.

[41] M irman, D., Q., Chen, Y. Zhang, et al. 2015. Neural organization of spoken language revealed by lesion-symptom mapping. Nat. Commun. 6: 6762.

[42] Turkeltaub, P. E., S. M essing, C. Norise, et al. 2011. Are networks for residual language function and recovery consistent across aphasic patients? Neurology 76: 1726-1734.

[43] Tillmann, B., K. Schultze \& J. M. Foxton. 2009. Congenital amusia: A short-term memory deficit for non-verbal, but not verbal sounds. Brain Cogn. 71: 259-264.

[44] Albouy, P., J. M attout, R. Bouet, et al. 2013. Does tonality boost short-term memory in congenital amusia? Brain 136: 1639-1661.

[45] Callan, D. E., V. Tsytsarev, T. Hanakawa, et al. 2006. Song and speech brain regions involved with perception and covert production. Neuroimage 31: 1327-1342.

[46] Brattico, E., V. Alluri, B. Bogert, et al. 2011. A functional M RI study of happy and sad emotions in music with and without lyrics. Front. Psychol. 2: 308.

[47] Alluri V., P. Toiviainen, T. E. Lund, et al. 2013. From Vivaldi to Beatles and back: Predicting lateralized brain responses to music. Neuroimage 83: 627-636.

[48] Wilson, B.A., J. Cockburn \& A. Baddeley. 1985 The Rivermead Behavioral Memory Test. Bury St-Edmunds, England: Thames Valley Company.

[49] Goodglass, H. \& E. Kaplan. 1983. The Assessment of Aphasia and Related Disorders, $2^{\text {nd }}$ ed., Philadelphia: Lea \& Febiger.

[50] Lezak, M.D., D.B. Howiesson, E.D. Bigler, et al. 2012. Neuropsychological Assessment, $5^{\text {th }}$ ed. New York, NY: Oxford University Press.

[51] De Renzi, E. \& P. Faglioni. 1978. Normative data and screening power of a shortened version of the Token Test. Cortex 14: 41-49.

[52] Laine, M., H. Goodglass, J. Niemi, et al. 1993. Adaptation of the Boston Diagnostic Aphasia Examination and the Boston Naming Test into Finnish. Scand. J. Log. Phon. 18: 83-92. 
[53] Peretz, I., A.S. Champod \& K. Hyde. 2003. Varieties of musical disorders. The M ontreal Battery of Evaluation of Amusia. Ann. N. Y. Acad. Sci. 999: 58-75.

[54] Mas-Herrero, E., J. M arco-Pallares, U. Lorenzo-Seva, et al. 2013. Individual differences in music reward experiences. Music Percept. 31: 118-138.

[55] Ferreri, L. \& L. Verga. 2016. Benefits of music on verbal learning and memory: How and when does it work? Music Percept. 34: 167-182.

[56] Wan, C.Y., T. Rüber, A. Hohmann, et al. 2010. The therapeutic effects of singing in neurological disorders. M usic Percept. 27: 287-295.

[57] Pihlaja, R., J. Uimonen, S. M ustanoja, et al. 2014. Post-stroke fatigue is associated with impaired processing speed and memory functions in first-ever stroke patients. J. Psychosom. Res. 77: 380-384.

[58] Ramsey, L.E., J.S. Siegel, C.E. Lang, et al. 2017. Behavioural clusters and predictors of performance during recovery from stroke. Nat. Hum. Behav. 1: 0038.

[59] Anderson, S., E. Himonides, K. Wise, et al. 2012. Is there potential for learning in amusia? A study of the effect of singing intervention in congenital amusia. Ann. N. Y. Acad. Sci. 1252: 345-353.

[60] Wilbiks, J. M., D. T. Vuvan, P. Girard, et al. 2016. Effects of vocal training in a musicophile with congenital amusia. Neurocase 22: 526-537. 


\section{Figure legends}

Figure 1. M elodies used in the sung part of the Sung-Spoken Story Recall Task at the acute (A) and 6-month (B) stage.

Figure 2. Percentage of correct responses (mean \pm SEM ) of the patients on the Sung-Spoken Story Recall Task separately for the spoken (grey bars) and sung (white bars) conditions at the (A) acute and (B) 6-month post-stroke stage. Results are shown for all patients and for aphasic, amusic, and memory impaired subgroups. Significant results in paired t-tests are indicated with asterisks.

Figure 3. Difference between the percentage of correct responses in the sung and spoken parts (sung minus spoken) of the Sung-Spoken Story Recall Task at acute (grey bars) and 6-month (white bars) post-stroke stage. Data is shown as mean \pm SEM . Results are shown for (A) non-aphasic / aphasic groups, (B) non-amusic / amusic groups, and (C) non-memory-impaired / memory impaired groups (paneled by Aphasia). Significant Time x Group interactions in mixed-model ANOVA are shown with asterisks. 


\begin{tabular}{|c|c|c|c|c|c|c|c|c|c|c|}
\hline \multirow[t]{2}{*}{ Demographic } & All & Aphasic & $\begin{array}{l}\text { Non- } \\
\text { aphasic }\end{array}$ & $P$ value & Amusic & $\begin{array}{l}\text { Non- } \\
\text { amusic }\end{array}$ & $P$ value & $\begin{array}{l}\text { Memory } \\
\text { deficit }\end{array}$ & $\begin{array}{l}\text { No } \\
\text { memory } \\
\text { deficit }\end{array}$ & \multirow[t]{2}{*}{$P$ value } \\
\hline & $N=31$ & $N=14$ & $N=17$ & & $N=16$ & $N=15$ & & $\mathrm{~N}=16$ & $\mathrm{~N}=15$ & \\
\hline \multicolumn{11}{|c|}{ Demographical variables } \\
\hline Age (years) & $\begin{array}{l}53.0 \\
(14.3)\end{array}$ & $\begin{array}{l}51.4 \\
(17.7)\end{array}$ & $\begin{array}{l}54.4 \\
(11.3)\end{array}$ & $0.564(t)$ & $\begin{array}{l}55.4 \\
(12.9)\end{array}$ & $\begin{array}{l}50.5 \\
(15.6)\end{array}$ & $0.365(t)$ & $\begin{array}{l}54.4 \\
(11.3)\end{array}$ & $\begin{array}{l}51.6 \\
(17.0)\end{array}$ & $0.599(\mathrm{t})$ \\
\hline $\begin{array}{l}\text { Gender } \\
\text { (male/female) }\end{array}$ & $19 / 12$ & $9 / 5$ & $10 / 7$ & $0.756\left(X^{2}\right)$ & $12 / 4$ & $7 / 8$ & $0.106\left(X^{2}\right)$ & $9 / 7$ & $10 / 5$ & $0.552\left(x^{2}\right)$ \\
\hline Education (years) & $\begin{array}{l}14.5 \\
(3.4)\end{array}$ & $\begin{array}{l}15.1 \\
(4.3)\end{array}$ & $\begin{array}{l}14.1 \\
(2.4)\end{array}$ & $0.428(t)$ & $\begin{array}{l}14.0 \\
(3.4)\end{array}$ & $\begin{array}{l}15.1 \\
(3.3)\end{array}$ & $0.344(t)$ & $\begin{array}{l}14.6 \\
(4.1)\end{array}$ & $\begin{array}{l}14.5 \\
(2.6)\end{array}$ & $0.375(\mathrm{t})$ \\
\hline \multicolumn{11}{|c|}{ Pre-stroke musical background } \\
\hline $\begin{array}{l}\text { Formal music } \\
\text { training (yes/no) }\end{array}$ & $8 / 23$ & $4 / 10$ & $4 / 13$ & $0.750\left(X^{2}\right)$ & $4 / 12$ & $4 / 11$ & $0.916\left(x^{2}\right)$ & $3 / 13$ & $5 / 10$ & $0.354\left(x^{2}\right)$ \\
\hline $\begin{array}{l}\text { Active singing or } \\
\text { playing (yes/no) }\end{array}$ & $15 / 16$ & $7 / 7$ & $8 / 9$ & $0.870\left(X^{2}\right)$ & $6 / 10$ & $9 / 6$ & $0.210\left(X^{2}\right)$ & $8 / 8$ & $7 / 8$ & $0.853\left(x^{2}\right)$ \\
\hline $\begin{array}{l}\text { BMRQ score } \\
(\max .100)\end{array}$ & $\begin{array}{l}75.6 \\
(12.6)\end{array}$ & $\begin{array}{l}77.6 \\
(11.5)\end{array}$ & $\begin{array}{l}74.0 \\
(13.7)\end{array}$ & $0.435(t)$ & $\begin{array}{l}77.0 \\
(10.7)\end{array}$ & $\begin{array}{l}74.2 \\
(14.7)\end{array}$ & $0.547(t)$ & $\begin{array}{l}74.8 \\
(13.2)\end{array}$ & $\begin{array}{l}76.5 \\
(12.4)\end{array}$ & $0.711(\mathrm{t})$ \\
\hline \multicolumn{11}{|c|}{ Pre-stroke leisure activities ${ }^{a}$} \\
\hline $\begin{array}{l}\text { Music listening } \\
\text { frequency }\end{array}$ & $\begin{array}{l}4.6 \\
(1.0)\end{array}$ & $\begin{array}{l}4.4 \\
(1.3)\end{array}$ & $\begin{array}{l}4.8 \\
(0.8)\end{array}$ & $0.245(t)$ & $\begin{array}{l}4.3 \\
(1.3)\end{array}$ & $\begin{array}{l}4.9 \\
(0.4)\end{array}$ & $0.106(t)$ & $\begin{array}{l}4.3 \\
(1.2)\end{array}$ & $\begin{array}{l}4.9 \\
(0.3)\end{array}$ & $0.046(t)$ \\
\hline $\begin{array}{l}\text { Radio listening } \\
\text { frequency }\end{array}$ & $\begin{array}{l}2.7 \\
(1.6)\end{array}$ & $\begin{array}{l}2.4 \\
(1.3)\end{array}$ & $\begin{array}{l}3.0 \\
(1.8)\end{array}$ & $0.328(t)$ & $\begin{array}{l}2.9 \\
(1.7)\end{array}$ & $\begin{array}{l}2.5 \\
(1.6)\end{array}$ & $0.489(t)$ & $\begin{array}{l}2.3 \\
(1.6)\end{array}$ & $\begin{array}{l}3.3 \\
(1.4)\end{array}$ & $0.075(\mathrm{t})$ \\
\hline $\begin{array}{l}\text { Reading } \\
\text { frequency }\end{array}$ & $\begin{array}{l}3.8 \\
(1.7)\end{array}$ & $\begin{array}{l}3.9 \\
(1.4)\end{array}$ & $\begin{array}{l}3.8 \\
(2.0)\end{array}$ & $0.958(t)$ & $\begin{array}{l}3.9 \\
(1.7)\end{array}$ & $\begin{array}{l}3.7 \\
(1.8)\end{array}$ & $0.747(\mathrm{t})$ & $\begin{array}{l}3.4 \\
(1.9)\end{array}$ & $\begin{array}{l}4.3 \\
(1.4)\end{array}$ & $0.183(\mathrm{t})$ \\
\hline \multicolumn{11}{|c|}{ Clinical variables (acute post-stroke stage) } \\
\hline $\begin{array}{l}\text { Lesion laterality } \\
\text { (left/right) }\end{array}$ & $20 / 11$ & $14 / 0$ & $6 / 11$ & $0.001\left(X^{2}\right)$ & $8 / 8$ & $12 / 3$ & $0.081\left(X^{2}\right)$ & $12 / 4$ & $8 / 7$ & $0.208\left(x^{2}\right)$ \\
\hline Lesion size $\left(\mathrm{cm}^{3}\right)$ & $\begin{array}{l}53.4 \\
(54.5)\end{array}$ & $\begin{array}{l}39.0 \\
(50.4)\end{array}$ & $\begin{array}{l}65.3 \\
(56.2)\end{array}$ & $0.186(t)$ & $\begin{array}{l}63.6 \\
(58.1)\end{array}$ & $\begin{array}{l}42.6 \\
(50.0)\end{array}$ & $0.292(\mathrm{t})$ & $\begin{array}{l}60.9 \\
(55.5)\end{array}$ & $\begin{array}{l}45.5 \\
(54.0)\end{array}$ & $0.439(\mathrm{t})$ \\
\hline $\begin{array}{l}\text { Stroke type } \\
\text { (infarct / } \\
\text { hemorrhage) }\end{array}$ & $22 / 9$ & $9 / 5$ & $13 / 4$ & $0.457\left(X^{2}\right)$ & $12 / 4$ & $10 / 5$ & $0.609\left(x^{2}\right)$ & $10 / 6$ & $12 / 3$ & $0.283\left(X^{2}\right)$ \\
\hline $\begin{array}{l}\text { NIHSS score } \\
(\max .42)\end{array}$ & $\begin{array}{l}4.7 \\
(3.1)\end{array}$ & $\begin{array}{l}3.9 \\
(2.3)\end{array}$ & $\begin{array}{l}5.5 \\
(3.6)\end{array}$ & $0.158(t)$ & $\begin{array}{l}6.0 \\
(3.6)\end{array}$ & $\begin{array}{l}3.4 \\
(1.9)\end{array}$ & $0.018(t)$ & $\begin{array}{l}5,0 \\
(3.2)\end{array}$ & $\begin{array}{l}4.5 \\
(3.2)\end{array}$ & $0.644(\mathrm{t})$ \\
\hline $\begin{array}{l}\text { BDAE severity } \\
\text { rating scale } 6 \\
\text { levels }\end{array}$ & $\begin{array}{l}4.3 \\
(0.7)\end{array}$ & $\begin{array}{l}3.7 \\
(0.5)\end{array}$ & $\begin{array}{l}4.8 \\
(0.4)\end{array}$ & $<0.001(t)$ & $\begin{array}{l}4.0 \\
(0.7)\end{array}$ & $\begin{array}{l}4.6 \\
(0.5)\end{array}$ & $0.013(t)$ & $\begin{array}{l}4.1 \\
(0.7)\end{array}$ & $\begin{array}{l}4,5 \\
(0.6)\end{array}$ & $0.057(t)$ \\
\hline
\end{tabular}




\begin{tabular}{|c|c|c|c|c|c|c|c|c|c|c|}
\hline $\begin{array}{l}\text { MBEA_Scale } \\
\text { and Rhythm } \\
\text { average } \\
\text { percentage }\end{array}$ & $\begin{array}{l}72.9 \\
(14.1)\end{array}$ & $\begin{array}{l}73.9 \\
(9.9)\end{array}$ & $\begin{array}{l}72.1 \\
(17.1)\end{array}$ & $0.720(\mathrm{t})$ & $\begin{array}{l}61.3 \\
(8.9)\end{array}$ & $\begin{array}{l}85.3 \\
(4.5)\end{array}$ & $<0.001(\mathrm{t})$ & $\begin{array}{l}71.9 \\
(14.4)\end{array}$ & $\begin{array}{l}74.0 \\
(14.1)\end{array}$ & $0.682(t)$ \\
\hline $\begin{array}{l}\text { AVLT learning } \\
\text { score ( } 3 \text { trials, } \\
\text { max. } 30 \text { ) }\end{array}$ & $\begin{array}{l}18.0 \\
(4.6)\end{array}$ & $\begin{array}{l}15.6 \\
(4.0)\end{array}$ & $\begin{array}{l}20.0 \\
(4.2)\end{array}$ & $0.006(t)$ & $\begin{array}{l}17.4 \\
(5.4)\end{array}$ & $\begin{array}{l}18.7 \\
(3.7)\end{array}$ & $0.466(\mathrm{t})$ & $\begin{array}{l}15.4 \\
(4.0)\end{array}$ & $\begin{array}{l}20.9 \\
(3.4)\end{array}$ & $<0.001(\mathrm{t})$ \\
\hline $\begin{array}{l}\text { AVLT delayed } \\
\text { recall score (max. } \\
\text { 10) }\end{array}$ & $\begin{array}{l}4.5 \\
(2.7)\end{array}$ & $\begin{array}{l}3.4 \\
(2.4)\end{array}$ & $\begin{array}{l}5.4 \\
(2.7)\end{array}$ & $0.049(\mathrm{t})$ & $\begin{array}{c}4.1 \\
(2.9)\end{array}$ & $\begin{array}{l}4.9 \\
(2.6)\end{array}$ & $0.459(\mathrm{t})$ & $\begin{array}{l}2.9 \\
(2.5)\end{array}$ & $\begin{array}{l}6.1 \\
(1.9)\end{array}$ & $<0.001(\mathrm{t})$ \\
\hline $\begin{array}{l}\text { RBMT story recall } \\
\text { immediate (max. } \\
\text { 42) }\end{array}$ & $\begin{array}{l}13.9 \\
(7.0)\end{array}$ & $\begin{array}{l}12.0 \\
(6.0)\end{array}$ & $\begin{array}{l}15.5 \\
(7.6)\end{array}$ & $0.174(\mathrm{t})$ & $\begin{array}{l}14.1 \\
(7.4)\end{array}$ & $\begin{array}{l}13.7 \\
(6.8)\end{array}$ & $0.899(\mathrm{t})$ & $\begin{array}{l}8.8 \\
(3.5)\end{array}$ & $\begin{array}{l}19.3 \\
(5.6)\end{array}$ & $<0.001(\mathrm{t})$ \\
\hline $\begin{array}{l}\text { RBMT story recall } \\
\text { delayed (max. } 42 \text { ) }\end{array}$ & $\begin{array}{l}11.1 \\
(7.5)\end{array}$ & $\begin{array}{l}8.6 \\
(5.3)\end{array}$ & $\begin{array}{l}13.1 \\
(8.6)\end{array}$ & $0.104(\mathrm{t})$ & $\begin{array}{l}10.1 \\
(7.7)\end{array}$ & $\begin{array}{l}12.1 \\
(7.4)\end{array}$ & $0.482(\mathrm{t})$ & $\begin{array}{l}5.8 \\
(3.6)\end{array}$ & $\begin{array}{l}16.7 \\
(6.5)\end{array}$ & $<0.001(\mathrm{t})$ \\
\hline
\end{tabular}

Data are reported as mean (SD) unless otherwise stated. Abbreviations: $t=$ independent-samples $t$-test, $X^{2}$ = chi-square test, $\mathrm{AVLT}=$ Auditory Wordlist Learning Task, $\mathrm{BMRQ}=$ Barcelona Music Reward

Questionnaire, NIHSS = National Institute of Health Stroke Scale, BDAE= Boston Diagnostic Aphasia

Examination, severity rating scale 0-6, MBEA= Montreal Battery of Evaluation of Amusia, RBMT =

Rivermead Behavioural Memory Test

aLikert scale 1-7 ( $1=$ not at all, $7=$ daily $)$ 
A. ACUTE STAGE

All $(\mathrm{N}=31)$

Aphasic ( $\mathrm{N}=14)$

Amusic ( $\mathrm{N}=16)$

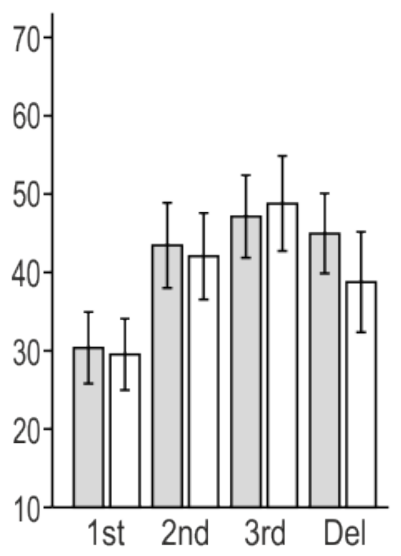

Memory-impaired ( $N=16)$

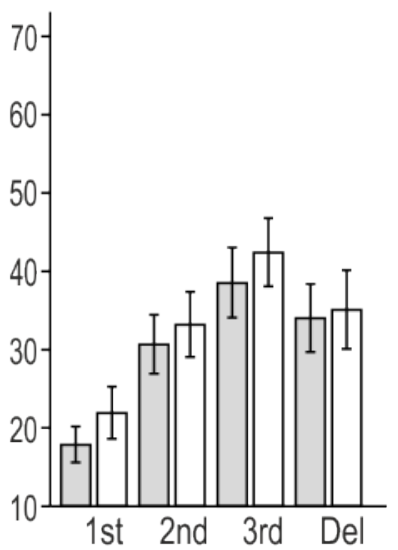

\section{B. 6-MONTH STAGE}

All $(\mathrm{N}=31)$

Aphasic ( $\mathrm{N}=14$ )

Amusic $(\mathrm{N}=16)$

Memory-impaired $(\mathrm{N}=16)$

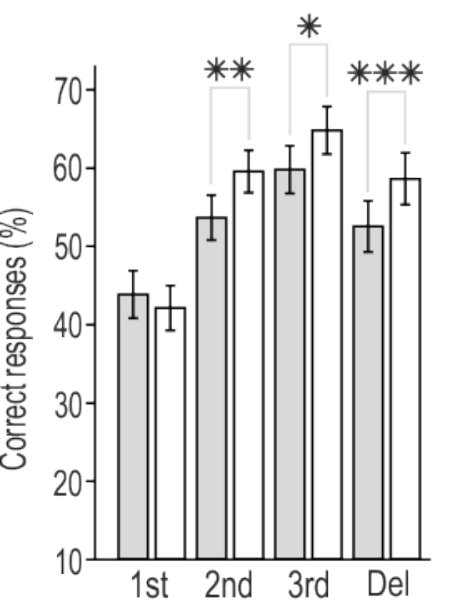

* $\quad$ *
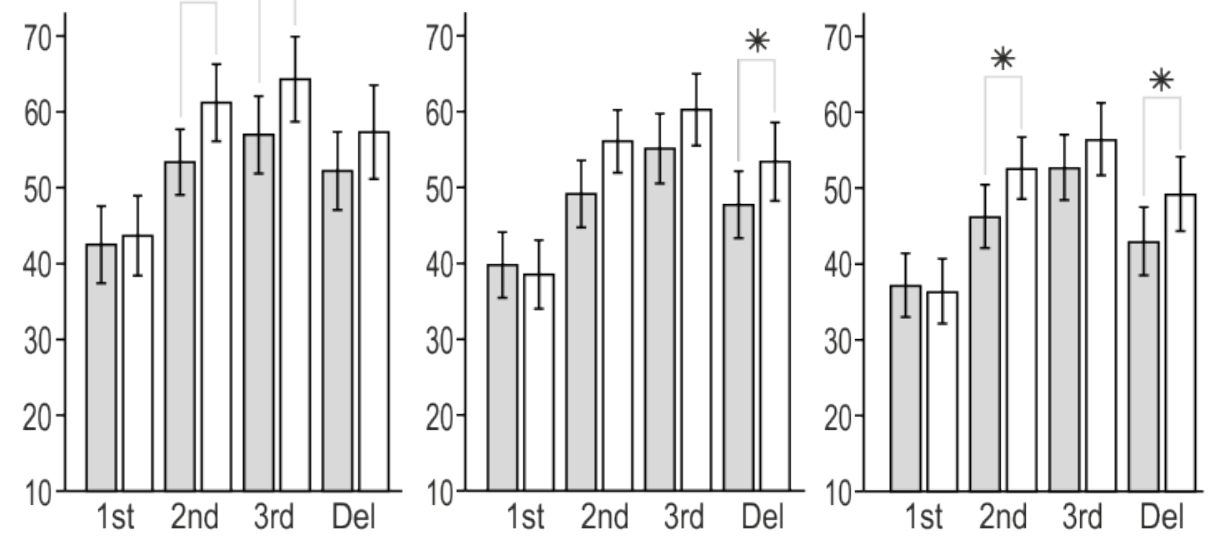
Melody S 1-2

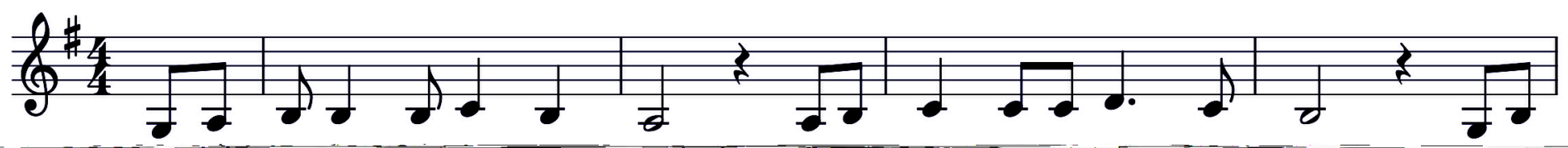

